\title{
Correspondence
}

\section{Arrhythmia and Charcot-Marie-Tooth disease during anesthesia}

To the Editor:

A 9-yr-old boy with known Charcot-Marie-Tooth Disease (CMTD) was scheduled for bilateral plantar fascia and toe releases. The anesthetic management included induction with thiopental and atracurium and maintenance with nitrous oxide/oxygen (60/40) and halothane (1-2\%) via an endotracheal tube. During the first plantar release, frequent premature ventricular contractions (PVC) with several distinct morphologies were identified. When couplets and groups of 2-3 PVCs were noted, the surgeons were asked to stop stimulation. Couplets ceased and PVCs decreased, only to return when surgical stimulation was resumed. The inhalation agent was changed to isoflurane. Couplets again disappeared and PVCs stabilized. Another episode of frequent, multi-focal PVCs occurred during emergence, which resolved shortly after extubation. A 12lead ECG revealed prolonged Q-T interval. The next morning, a repeat ECG revealed normal Q-T interval with no other abnormalities.

Although the arrhythmia that occurred during this case was a surprise, it is consistent with other CMTD cases where cardiac abnormalities were detected, including paroxysmal atrial flutter, ${ }^{1}$ cardiomyopathy ${ }^{2}$ and complete A-V block. ${ }^{3}$ Other features of this case could have contributed to the cause of arrhythmia. Metabolic changes with polyneuropathy could cause conduction abnormalities. Halothane is known to increase arrhythmia and decrease the speed of conduction within the conduction system. ${ }^{4}$ The occurrence of these events was coincident with intervals of maximal stimulation; light anesthesia could have triggered arrhythmia.

Patients with CMTD may have unrecognized cardiac conduction abnormalities. Intraoperative management should include prompt recognition and increased vigilance during anesthetic techniques that predispose to arrhythmia.

John E. Tetzlaff MD

Ivan Schwendt MD

Cleveland, Ohio, USA

References

1 Leak D. Paroxysmal atrial flutter in peroneal muscle atrophy. Br Heart J 1961; 23: 326-8.
2 Lascelles RG, Baker IA, Thomas PK. Hereditary polyneuropathy of Roussy-Levy type with associated cardiomyopathy. Guy's Hospital Report 1970; 119: 253-62.

3 Rosselot E, Brinck G Conduction system disease and Charcot-Marie-Tooth syndrome. (Spanish) Rev Med Chil 1989; 117: 914-7.

4 Blayney M, Malins AF, Cooper GM Cardiac arrhythmia in children during outpatient general anaesthesia for dentistry: a prospective randomised trial. Lancet 1999; 354: 1864-6.

\section{Dysfonctionnement de pacemaker se- condaire à une cassure traumatique du boîtier}

A la suite d'un accident de la voie publique, un conducteur de 74 ans (qui ne portait pas la ceinture de sécurité) a présenté un traumatisme majeur avec volet thoracique droit. Un bloc auriculo-ventriculaire (BAV) complet avait nécessité en 1991 la mise en place d'un pacemaker double chambre, changé 15 jours auparavant de manière systématique, pour usure normale de la pile (Stimulateur Double Chambre Asservi TRILOGY $\mathrm{DR}+2364 \mathrm{~L}-$ Pacesetter). La vérification télémétrique du pacemaker, motivée par la réapparition d'un BAV complet après l'accident, concluait à l'intégrité du boîtier et à une rupture des 2 sondes, probablement au niveau du boîtier car non visible à la radiographie. L'instabilité clinique de ce patient ne permettait pas d'envisager le changement du pacemaker. Malheureusement, malgré un traitement par isoproterenol, le patient décédait huit jours après son admission dans un tableau de choc septique. Le diagnostic de cassure du pacemaker entre la boîte de branchement du stimulateur et le stimulateur lui-même était porté au cours de l'ablation post-mortem (Figure; la tête de ce type de pacemaker est collée, non vissée).

Les dysfonctionnements des pacemakers au cours d'accidents de la voie publique sont le plus souvent secondaires à une section ou une malposition visible à la radiographie des électrodes ${ }^{1}$ ou à une cassure de certains composants électriques internes. ${ }^{2}$ En revanche, à notre connaissance, c'est la première fois qu'une cassure de boîtier est rapportée. Les fractures de pacemakers existent et il faut savoir y penser lors 


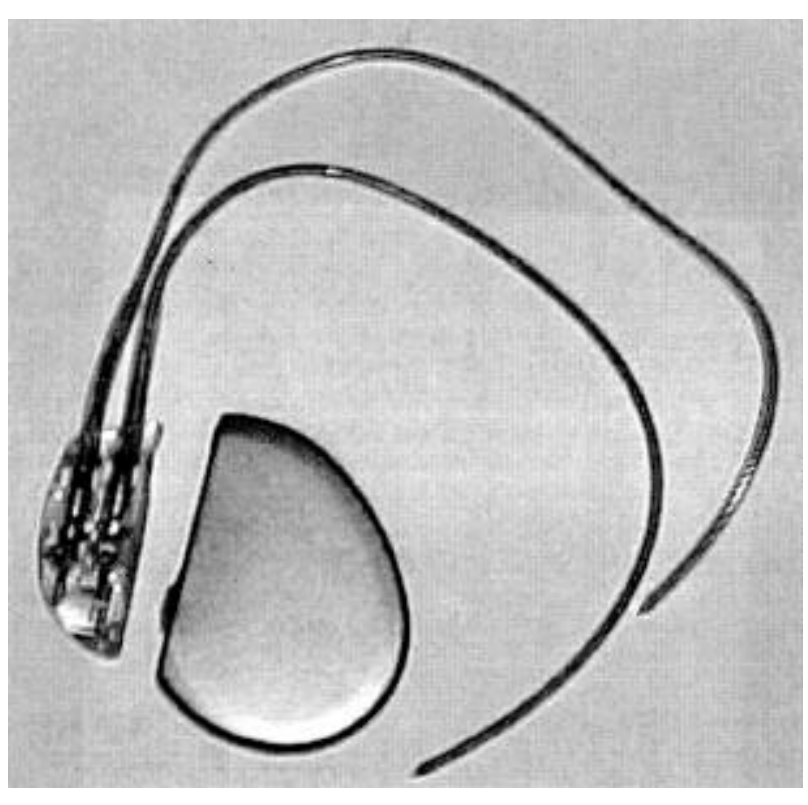

FIGURE Photographie montrant la cassure du pacemaker au niveau du boîtier

d'un dysfonctionnement secondaire à un accident de la voie publique sans section décelable des électrodes.

R. Fuzier MD

B. Chaminade MD

V. Mercier-Fuzier MD

B. Georges MD

J.F. Decun MD

P. Cougot MD

C. Virenque MD MPH

Toulouse, France

References

1 Lasky II. Pacemaker failure from automobile accident. JAMA 1970; 211: 1700.

2 Brown KR, Carter W Jr, Lombardi GE. Blunt traumainduced pacemaker failure. Ann Emerg Med 1991; 20: 905-7.

\section{Sedation for MRI scans in children}

To the Editor:

The concept of nurses giving sedation to pediatric patients for MRI scans causes me great concern for the safety of the patients and especially in Canada, for the efficient use of MRI scan time.
Beebe et al. took great care to train the nurses involved and experience improved the performance of everyone involved. However, their average sedation time of $69 \pm 32 \mathrm{~min}$ for scans of 20 to $30 \mathrm{~min}$, and their recovery times of $60+$ min would be problematic in our institution. Supervision by a radiologist gives me cause for concern, because they are not likely to be accustomed to airway management in emergency situations as can occur in the MRI setting. I believe that it is important that anesthesiologists must not abrogate their responsibilities to patients, even when it appears that nurses might do the job in the majority of situations.

I have been giving anesthetics to patients for MRI scans one day per week since 1991 and have anesthetized about 5000 patents in that time using propofol. My median sedation time is $34 \mathrm{~min}$, with a median recovery time of $25 \mathrm{~min}$. I have had two failures, both in patients in whom I could not establish an $i v$. Airway management is the major challenge; most patients are managed with optimal head and neck positioning, but some require oropharyngeal airways, some require laryngeal masks and, a very few require tracheal intubation. None have required neuromuscular blocking agents.

Patients requiring sedation or anesthesia for MRI scans should be treated by an anesthesiologist who should decide upon the appropriate technique.

Ross E. Harrison MD FRCPC

Calgary, Alberta

\section{REPLY:}

Dr. Harrison and his colleagues perform sedation for MRI in pediatric patients using intravenous propofol. He reports very few failures and much more rapid recovery (25 min) than we obtained using our protocol (69 min). He also states that he and his colleagues are better able to provide airway management, if the need arises, than nurses or radiologists.

I agree that propofol, administered by an anesthesiologist, will result in quicker recover and discharge than most sedation protocols. Most protocols, like ours, primarily use barbiturates or chloral hydrate. Unfortunately, most institutions do not have enough anesthesia personnel or resources to administer propofol and/or other sedative or general anesthetics to every child requiring sedation for MRI. Propofol administration can result in apnea relatively rapidly and, in my opinion, requires an anesthesiologist to be present. In contrast, the agents in most sedation protocols have a more gradual onset, and have a long safety record when administered by nurses. ${ }^{1,2}$ 